Article

\title{
Transferring Circular Economy Solutions across Differentiated Territories: Understanding and Overcoming the Barriers for Knowledge Transfer
}

\author{
Marcin Dąbrowski ${ }^{1, *}$, Viktor Varjú ${ }^{2}$ and Libera Amenta ${ }^{3}$ \\ ${ }^{1}$ Department of Urbanism, Faculty of Architecture and the Built Environment, Delft University of Technology, 2628 Delft, \\ The Netherlands; E-Mail: m.m.dabrowski@tudelft.nl \\ 2 Institute for Regional Studies, MTA KRTK, 7621 Pécs, Hungary; E-Mail: varju@rkk.hu \\ ${ }^{3}$ Department of Architecture, University of Naples Federico II, 80134 Naples, Italy; E-Mail: libera.amenta@unina.it \\ * Corresponding author
}

Submitted: 31 March 2019 | Accepted: 19 July 2019 | Published: 27 September 2019

\begin{abstract}
"Learning from abroad" is a widely recognised and used means to innovate and improve strategies and policies implemented by regions and cities. However, literature on knowledge transfer and related concepts, such as policy transfer, policy mobility or lesson-drawing, highlights the limitations of this process, especially when it entails the simple transfer of (best) practices from "place A" to "place B". Such a transfer may lead to suboptimal solutions particularly when the imported practices concern complex phenomena, involving networks of multiple actors and relying on place-specific dynamics. Departing from this critique, the article sheds light on the process of knowledge transfer in the field of circular economy, taking place between the two metropolitan regions of Amsterdam and Naples. This process is guided by an innovative methodology based on a network of (peri-urban) living labs generating eco-innovative solutions for using material waste and wastescapes as a resource in peri-urban areas. Using participant observation in knowledge transfer workshops, stakeholder interviews and surveys, it investigates how the process of co-creation of knowledge in the relational space of the networked living labs takes place thanks to the participation of stakeholders from both regions. This in turn allows for drawing conclusions on what barriers are encountered in such knowledge transfer, what makes solutions transferable across different contexts, and, finally, how the solutions are adapted as they travel from one place to another.
\end{abstract}

\section{Keywords}

Amsterdam; circular economy; eco-innovative solutions; knowledge transfer; living labs; Naples; policy mobility; policy transfer; policy translation

\section{Issue}

This article is part of the issue "Facilitating Circular Economy in Urban Planning", edited by Hilde Remoy (Delft University of Technology, The Netherlands), Alexander Wandl (Delft University of Technology, The Netherlands) and Denis Ceric (Polish Academy of Sciences, Poland).

(C) 2019 by the authors; licensee Cogitatio (Lisbon, Portugal). This article is licensed under a Creative Commons Attribution 4.0 International License (CC BY).

\section{Introduction}

Transfer of knowledge, policies or "best practices" from different territories aimed at addressing policy challenges, has become a standard feature of contemporary policy-making. Urban planners and decision-makers seeking solutions to local problems abroad and striving to learn from foreign experiences to improve domestic policies is widespread (Healey \& Upton, 2010), even if this process is riddled with uncertainty regarding the fit of a foreign solution in the recipient context (Dolowitz \& Marsh, 2000). In fact, despite the differences between the "sender" and "recipient" contexts, foreign experience can provide a useful source of inspiration, cautionary tales, ideas, understanding or concrete measures, which can enrich the spectrum of possibilities and the knowledge pool available to decision-makers.

Knowledge transfer from abroad is particularly relevant in the case of new kinds of policies and solutions, where there may be little "home-grown" experience, as 
is the case with eco-innovative strategies and solutions for promoting a circular economy. A circular economy can be defined as a "regenerative system in which resource input and waste emission and energy leakage are minimised by slowing, closing, and narrowing material and energy loops. This can be achieved through long-lasting design, maintenance, repair, reuse, remanufacturing, refurbishing, and recycling" (Geissdoerfer, Savaget, Bocken, \& Hultink, 2017, p. 759).

This concept is taken up in a growing number of policies and strategies of national, regional and local governments; however, it is far from being a mature policy field. Moreover, there is little experience and knowledge of its implementation in spatial strategies. There is, therefore, a strong interest among policy-makers and planners in learning from international experiences in this field, while there has been no research to date on the transfer of knowledge in this emerging policy field across differentiated territorial contexts.

Knowledge transfer, however, is a process riddled with uncertainty and difficulties. As highlighted in the literature on inter-organisational knowledge transfer (e.g., Argote \& Fahrenkopf, 2016), and the bodies of theory and knowledge on the related concepts of policy transfer (e.g., Dolowitz \& Marsh, 2000), policy translation (e.g., Stone, 2012), or learning from best practice (e.g., Stead, 2012), transferring policy solutions from abroad can lead to policy failure at home. Therefore, from the practice perspective, there is a need for careful consideration of the context in which the original solutions emerge and of how they can be adapted to the recipient context. There is, however, a research gap concerning: (1) the transferability of solutions between contexts, and (2) the understanding of how solutions are adapted and morphed as they are grafted from one place to another.

Against this background, the article strives to address the above gaps and answer following three research questions: (1) What are the barriers for transfer of circular economy solutions across different regions? (2) What makes solutions transferable between differentiated regional contexts? (3) How do solutions change and adapt in the process of transfer?

To address these questions, the article draws on novel empirical material from the knowledge transfer process on spatial solutions for promoting circular economy between two contrasted European metropolitan regions (Amsterdam Metropolitan Area [AMA] and the Naples Metropolitan Area), experimenting with ecoinnovative solutions (EIS) for circular resources management. The process is unique insofar as it takes place within a network of six living labs (Steen \& van Bueren, 2017), bringing together stakeholders to coexplore circularity challenges and co-create spatial solutions to promote circular economy in a real-world context. Living labs are "user-centred, open innovation ecosystems based on a systematic user co-creation approach in public-private-people partnerships, integrating research and innovation processes in real-life commu- nities and settings" (ENoLL, 2019). In the case of this research, the living labs located in different urban regions also provide a "networked laboratory" for studying and promoting knowledge transfer. The empirical material on which this article builds, collected through participant observation within living lab workshops, interviews and surveys with the living labs participants, offers unique insight into this topic.

The remainder of the article is organised as follows: Section 2 offers a review and critique of knowledge transfer and related concepts. Then, on that basis, the methodology for the article is outlined in Section 3. This is followed by the empirical section unpacking the knowledge transfer process between the regions of Amsterdam and Naples in Section 4. Finally, the concluding Section 5 summarises and discusses the findings, draws lessons for practice and outlines avenues for further investigation.

\section{Knowledge Transfer: How to Make It Work?}

Knowledge transfer is a term which originated in organisation studies, where it was used to study how knowledge 'travels' between firms and contributes to innovation processes. According to Argote and Ingram (2000, p. 151): "Knowledge transfer in organisations is the process through which one unit (e.g., group, department, or division) is affected by the experience of another". Knowledge transfer is conditioned by structural network features like the strength of the ties between the actors and their stability, but also cognitive characteristics like shared goals or trust between them (Inkpen \& Tsang, 2005). It is collaboration, open communication, and trust between the actors involved that support effective knowledge transfer. As such, partnering between organisations is a means to achieve this (Bellini, Aarseth, \& Hosseini, 2016). However, there remains a major gap in the literature on knowledge transfer insofar as it struggles to explain how organisations identify what is relevant and suitable to transfer (Argote \& Fahrenkopf, 2016). Moreover, it is worth stressing that knowledge transfer across differentiated contexts "implies the transformation of both the target context and knowledge content...through processes of translation, negotiation and bargaining among actors" (Yakhlef, 2007, p. 44). Thus, knowledge content is modified as it 'travels'. In this study, the emphasis is thus on understanding how EISs for a circular economy are adapted to the recipient context in the process of transfer.

The concept of 'policy transfer' (Dolowitz \& Marsh, 2000), related to knowledge transfer, also informs this study. Policy transfer explores "how policies, administrative arrangements, institutions and ideas in one political setting (past or present) are used in the development of policies, administrative arrangements, institutions and ideas in another political setting" (Dolowitz \& Marsh, 2000 , p. 5). Transfer, however, may lead to policy failure when it is done without adaptation to recipient context 
or there is a lack of structural conditions, knowledge or resources to make it work. In a similar vein, Evans (2009) was also interested in what could make policy transfer unsuccessful and conceptualised the potential obstacles for this process, distinguishing cognitive barriers (related to, e.g., a shallow understanding of the practice transferred), environmental barriers (related to the process of transfer, e.g., lack of platforms for transfer) and public opinion barriers (opposing transfer). In this study, specific barriers for transfer of solutions for a circular economy are explored.

The policy transfer literature, while being extremely influential, has been criticised for disregarding how practices and norms are changed and adapted to the local context during the adoption process (Stone, 2012), as well as the question of what is actually transferred and why (Howlett \& Rayner, 2008). Beyond this research gap, there is also little recognition of the problems associated with the circulation of best practice without due consideration of its suitability for the recipient context. In fact, lack of knowledge on how such best practice emerged, what other options that were pondered, which process that lead to this and its possible failures or u-turns creates a risk of misinformed transfer and ultimately failure of the adopted solutions (Stead, 2012). Some policies are so deeply embedded in the peculiar national legal, political, or social systems that they are simply not transferable (Stone, 2012).

This led to a growing interest in 'policy translation' (see Stone, 2012), as opposed to transfer as a simple linear copy-paste process from 'place $A$ ' to 'place $B$ '. Thus, in the process of translation of a foreign practice to the local 'language', hybridisation and learning processes take place, which in turn can lead to the emergence of new policy meanings and a significant departure from the original imported policy. This can have the merit of resulting in "a more coherent transfer of ideas, policies and practices" (Stone, 2012, p. 488). In parallel, geographers have been exploring the process of 'policy mobility', which is concerned with the linking global circuits of policy knowledge to local policy practice, politics, and actors and exploring what happens along the way as the policies are transferred from place to place (e.g., McCann, 2011). The emphasis here is on policy mobility networks, while recognising the importance of spatial nodes in which these networks are anchored.

Building on the notion of policy translation, this study focuses on exploring how EIS for achieving circularity are translated to best fit into the recipient context (see Stone, 2012). It also explores how the process of transfer is moored in a set of networked living labs providing a platform for collaboration between stakeholders from different territories (see Bellini et al., 2016) and establishing socio-spatial nodes where transfer takes place, solutions emerge, hybridise and morph as they 'travel'. The latter endeavour is loosely inspired by policy mobility literature (e.g., Peck, 2011; Temenos \& McCann, 2013), borrowing the notion of international networks being moored in space and applying it describe the network of the living labs as part of the REPAIR project, in which the knowledge transfer activities unfolded, albeit without deeply engaging with this strand of the literature. ${ }^{1}$

\section{Methodology: Living Labs as a Knowledge Transfer Platform}

The use of living labs for user-centric innovative planning processes (see van Geenhuizen, 2018) began in Europe circa 2000 (see, e.g., Lepik, Krigul, \& Terk, 2010; REPAiR, 2017). The concept has since then been widely applied to foster urban experimentation across Europe and the world (Steen \& van Bueren, 2017), providing a methodology for fostering open innovation and knowledge co-creation (Lepik et al., 2010). Living labs bring users/consumers/citizens into the system of innovation, thereby leveraging on a larger mass of ideas, knowledge and experiences (Eriksson, Niitamo, Kulkki, \& Hribernik, 2006, p. 1). In the Horizon 2020 REPAiR project, on which this article builds, Peri-Urban Living Labs (PULLs) were set up across six European regions ${ }^{2}$ to engage stakeholders in co-creation of circular economy solutions for these regions. The stakeholders in each of the regions were selected by the project consortium partners based on the waste management topics and material flows investigated in the given case. Thus, stakeholders included a range of experts dealing with the said topics and flows from for-profit, non-profit, university sectors were identified by the researchers running each living lab and were invited to the workshops. The participation activities of stakeholders varied across workshops and case study regions, albeit within the framework of the predefined methodologies for the living labs and for knowledge transfer events within them. Some of the stakeholders were involved in all of the workshops, while the participation of others was less regular. Experts from other case study regions also take part both in the early phase of each PULL process and later in so-called 'knowledge transfer events'. The role of these foreign stakeholders is crucial because during the early phase of co-creation process they can work in their own experience and ideas

\footnotetext{
${ }_{1}^{1}$ Policy mobilities literature typically takes a critical stance on these processes, pointing to contested questions regarding the interest and agendas of the actors involved in policy mobility, whereas the researchers conducting this study were directly involved in the transfer process as part of a major research consortium, seeking to explore how to make the transfer of solutions across the participating regions more strategic and purposeful.

2 For the REPAiR project, six peri-urban areas have been chosen in order to allow a comparison of (three) different urban scales with similar (e.g., in recycling rate) and different challenges (e.g., dominancy of organic versus C\&D waste flows). In every phase of the project-including the PULLs' organisation and the knowledge transfer events-a two-step approach has been applied. After the test of tasks in the work packages in the two (similar) pilot regions (AMA and the Naples Metropolitan Area) tasks were conducted in the follow-up regions (Ghent, Łódź, Hamburg and Pécs). In this article, however, we are focusing only on the knowledge transfer between the two pilot regions. For more on REPAIR methodology see: http://h2020repair.eu/aboutrepair/project-methodology
} 
from their region into the discussion. They also play a vital role in the said knowledge transfer events. Besides explaining the EIS (EC, 2011, 2012) from their regions to be transferred, the 'sender stakeholder' can explain the socio-cultural, geographical, historical background of the region in which the EIS emerged. Moreover, the discussion on adaptations to the EIS required for its transfer can result in important feedback and lessons on how to further improve the original solution. Therefore, the PULLs network offers fertile soil for knowledge transfer because such labs are widely recognised as successful instruments for accelerating innovation in a real-world context, co-creating and improving innovative ideas for different case study areas (REPAiR, 2017). Furthermore, PULLs support effective knowledge transfer as they provide a platform for partnering between stakeholders from different regions (cf. Bellini et al., 2016).

By allowing for appreciation of both the sender and recipient contexts, this method responds to the call for more culturally and socially-constructed perspectives on learning across national boundaries (Dolowitz \& Marsh, 2012; McCann \& Ward, 2012), while spatialising the process of knowledge transfer by connecting it to PULLs' effort to design solutions for given territories. Thus, knowledge transfer via PULLs is moored to specific spatial nodes in the six peri-urban regions. It is in those nodes that solutions and implementation strategies are generated and transferred across cases (Figure 1), with translation to fit another context taking place (cf. Stone, 2012).

During the knowledge transfer events, a discussion was facilitated by moderators from both the sender and recipient regions and structured around a prepared template sheet outlining the eco-innovative solution to be transferred (see Figure 2) and its key constituent elements (e.g., waste flow, location, stakeholders involved, etc.). Thanks to the sheet-to be filled within the PULL workshops - and explanations provided by the sender region participants, the recipient region participants gained insight into the transferred solution and the context in which it emerged. Participants were asked to discuss and summarise, in written form, answers to questions to explore the scope and possibilities for transferring a given solution. The recipient region stakeholders were thus asked about the transferability of the EIS in general, the best locations for implementing the EIS, the barriers for transfer (based on their preliminary experiences and knowledge about the milieu of the recipient region), the adaptations needed and the local actors who should be involved in the implementation (Figure 2).

Data for this study was collected through participatory observation (participatory rapid assessment; cf. Russel, 2006) of the operation of the PULLs and knowledge transfer events. Instead of recording voice or audio, which would be difficult to analyse due to multiple languages (e.g., local language and English) being used at knowledge transfer events across the different PULLs, we relied on the descriptive recording of observations "under natural conditions" (Kumar, 2014). Hence, besides the questions in the knowledge transfer sheet (Figure 2) for the participatory observation, we elaborated a sheet for the observers (in the case study areas). In this sheet, observers were asked to categorise the stakeholders based on their affiliation (13 types), describe their dominant behaviour (rational or emotional), the attributes of the leading person of the group, the overall attitudes of the group towards the problem raised by the guest stakeholder (EIS sender), the types of barriers to transfer, the degree of transferability, the adaptations to EIS

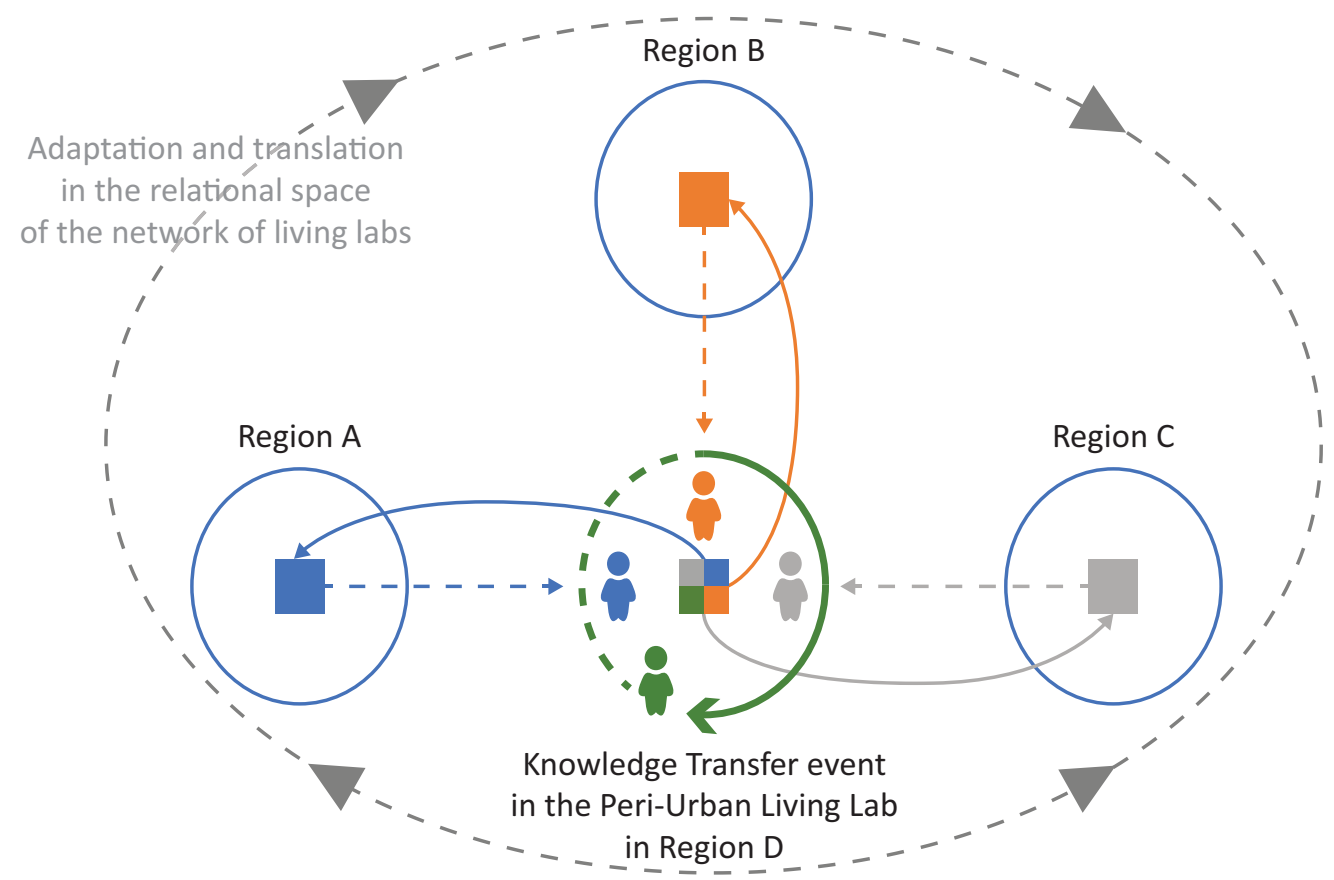

Figure 1. Co-creation and mobility of EIS in a network of living labs. Source: authors. 


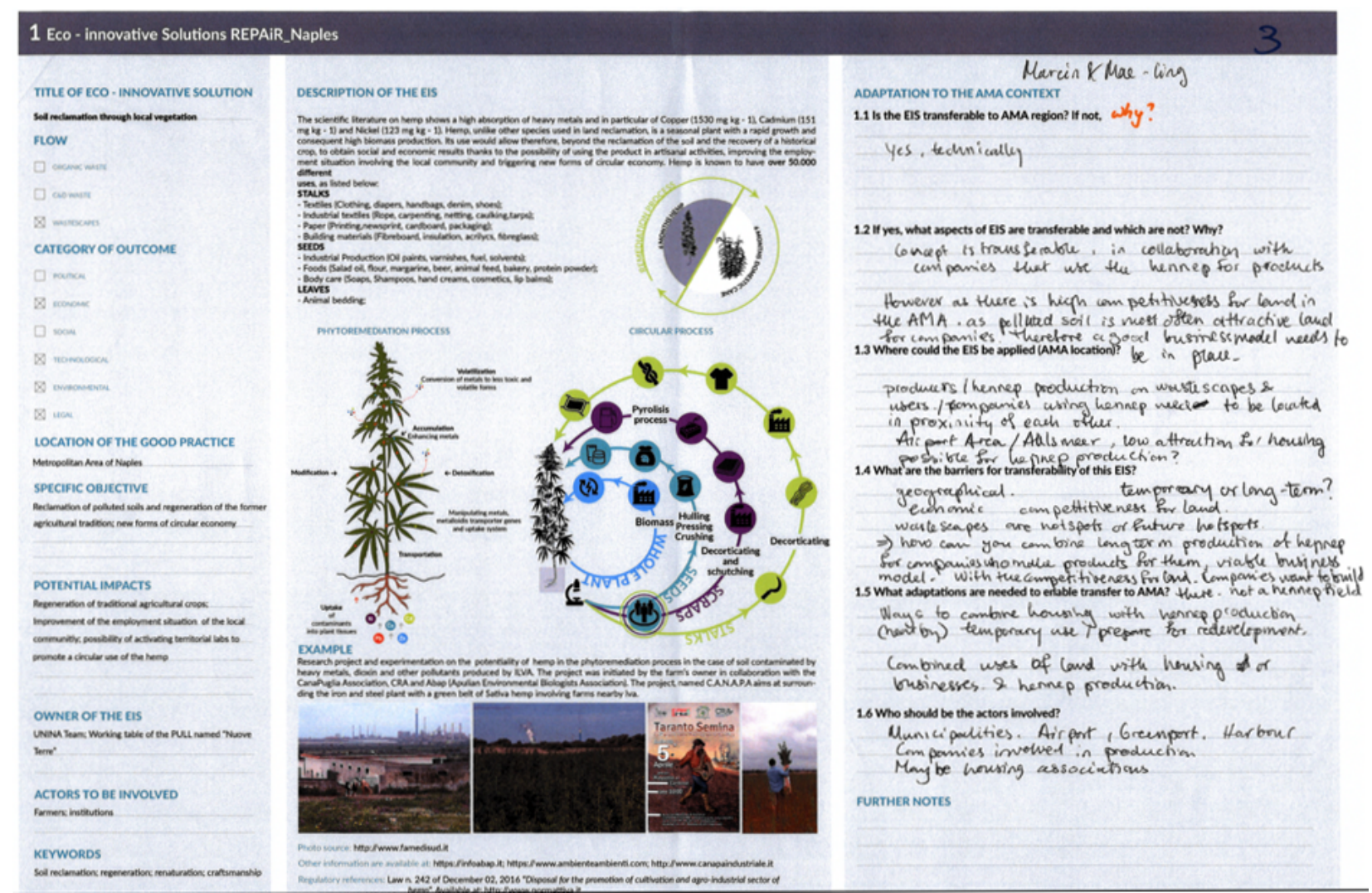

Figure 2. Example of a knowledge transfer sheet template for testing the EIS transferability, used in living lab workshops. Source: REPAIR project team.

proposed, the use of available time, etc. These all allowed for identifying the main peculiarities of knowledge transfer, analysing the dialogue and exchange of knowledge between stakeholders with a different territorial, disciplinary and socio-cultural background. The study entailed observation of interactions in a network of living labs unfolding over a period of about two years, giving enough time for relations of trust to emerge between the participants and allowing for exploring how the solutions emerged, travelled and morphed in the processes. Moreover, PULL workshops (in the two pilot cases) started and ended with a short questionnaire filled in by participants, including questions on the process of the knowledge transfer, the preferred knowledge transfer channels (e.g., study visit, webinar, workshops), and the evaluation of the PULL as a knowledge transfer channel. Finally, a short semi-structured follow-up Skype interviews were also conducted with visiting participants in order to gain further insights into the transferability of the solutions in the recipient regions and experiences of the process of transfer of knowledge in the PULLs.

\section{Unpacking the Knowledge Transfer Process}

Using the methods described above, the research aimed to reveal how knowledge (EIS in this case) can be transferred and adapted. It is important to note here, however, that the study did not scrutinise the implementa- tion of the transferred solutions, but rather focused on proposed sets of solutions designed in the Naples and Amsterdam PULLs and transferred between them. The transfer, hence, was intended to contribute to the work of each of those living labs and to the catalogues of EIS co-produced in them with the regional stakeholders. Investigation of the later possible implementation of the transferred solutions remains beyond the scope of the project on which this article draws.

It should also be stressed that both PULLs had a specific focus in terms of material flows and spatial conditions to consider in the solutions and strategies developed. Firstly, the spatial structures for which the EIS are developed can include wastescapes (underused/abandoned/polluted lands typically due to former industrial activities hosted, pollution and formal/informal waste dumping, proximity of infrastructures, etc.; see Amenta \& van Timmeren, 2018). Secondly, the EIS regard the flows of construction and demolition waste (C\&DW), which is the waste material that is produced through demolition processes and/or can be used in the construction of buildings and infrastructure, and organic waste flow.

\subsection{EIS to Be Transferred}

Knowledge transfer events were held both in Amsterdam, in 2018, and in Naples, in 2019. For each of 
them, stakeholders from the other region were invited to take part and brought with them a selection of EISs from their region. Since the EIS catalogues from each region (REPAiR, 2018a, 2018b) included several types of EISs focusing on several flows (e.g., organic waste, C\&DW, wastescapes), stakeholders in each region were asked to pre-select EISs able to address similar challenges that were identified in the earlier phase of their PULLs. EIS were pre-selected by the research teams from both regions on the basis of match of material flows and challenges to be addressed in both cases. Thus, the process of transfer from Naples to Amsterdam is illustrated with the cases of two EISs. The first one is entitled "RECALL: REmediation by Cultivating Areas in Living Landscapes" (henceforth mentioned as the RECALL solution), aiming at promoting the reclamation and eventually the reuse of polluted wastescapes through bioremediation of soil. This is done using hemp and other relevant crops (see REPAiR, 2018a). This solution tackles wastescapes, as well as the C\&DW flow. The original solution developed for the Naples region attempts to address the massive problem with polluted land remaining vacant or underused because of polluted soil (often due to illegal dumping of hazardous waste). The solution taps into the artisanal traditions of manufacturing a variety of products from hemp fibres (e.g., cloth, string) and the high capacity of hemp to extract heavy metal pollutants from soil. The process would make the polluted wastescapes suitable for reuse for residential or other compatible uses, while creating scope for recreating a traditional industry and creating jobs. The second EIS, called "REC.OVER: Free Eco-Lab for Construction and Demolition Waste Reuse" (henceforth mentioned as the REC.OVER solution), entailed creating a storage, sorting and marketplace facility for C\&DW, reusing a wastescape and providing individuals and small companies to deposit waste anonymously and for free (to tackle illegal dumping in Naples). The materials collected are classified according to a material passport and made available for purchase to local builders, while spreading knowledge on circular construction processes and creating new job opportunities.

The transfer from Amsterdam to Naples is illustrated by two examples of solutions for wastescape regeneration (REPAiR, 2018b), which were deemed the most transferable by the Naples PULL stakeholders: "Transformation of Wastescapes into Stepping Stones for Biodiversity" and "Transformation of Green Buffer Zones into Areas for Leisure Activities". They both aimed to reuse buffer zones of infrastructures in circular and creative ways for improving the quality of life in periurban areas, where large scale infrastructures can represent a threat for the environment and biodiversity (EEA European Environment Agency, 2017).

The first EIS aimed at reusing the underused areas within buffer zones of large infrastructure networks to increase their ecological value and biodiversity. In this way, plants and animals could use these 'sequential patches'.
Conversely, the second solution is meant for people, that could find alternative areas for recreation in the buffer zones of highways or railways.

\subsection{Understanding the Barriers to Knowledge Transfer}

Based on a systematic literature review, several types of barriers for knowledge transfer were identified and later verified through research on the process of knowledge transfer between Amsterdam and Naples PULLs. Besides language ('dummy' barrier), the disciplinary background of transfer actors, geographical features of the regions involved, socio-cultural, socio-economic, socio-political, or legal differences, governance/decisionmaking background, and level of technological development were identified as factors that can influence the transferability of circular EIS (REPAiR, 2018c). This typology of barriers to knowledge transfer is summarised below (Table 1).

\subsubsection{Naples to Amsterdam}

In the case of the transfer of the RECALL solution from Naples to Amsterdam, the workshops' participants identified the main geographical and socio-economic barriers: the scarcity of land and huge competition and demand for land for new developments in the AMA. The AMA has a substantial amount of polluted wastescapes, mainly in the port of Amsterdam terrain. However, land scarcity and huge demand for land for development limit the scope for application of soil bioremediation with hemp or other crops, unless it would be connected to other metabolic flows (for instance construction and demolition materials), broadening the economic appeal of the solution. Other more immediate uses for the wastescapes, like housing development or expansion of the Schiphol airport, with pollution removed simply by scraping off the layer of polluted land and dumping it elsewhere, may be economically more viable.

Major socio-cultural and socio-economic barriers were identified for the transfer of the REC.OVER solution from Naples to Amsterdam. The original EIS was designed to incentivise individuals to renovate their property or small building companies to avoid illegally dumping of C\&DW on the streets or in other open spaces, and instead bring it anonymously to the proposed collection points. The problem of illegal dumping is hardly present in the AMA, while the construction sector operates differently, with little individual activity and well-organised system of disposal, collection and recycling of C\&DW.

\subsubsection{Amsterdam to Naples}

The two solutions for valorising underused buffer zones from Amsterdam to Naples can easily be transferred, even if some barriers were identified. Firstly, for the solution where buffer zones are upgraded by the increase of biodiversity, the main issue was the availability of budget 
Table 1. Typology of barriers for knowledge transfer. Source: Adapted from REPAiR (2018c), building on Evans (2009), Heinelt et al. (2006), Marino, Parotta and Pozzoli (2016) and Schumacher (2015).

\begin{tabular}{ll}
\hline Barrier & How it hinders transferability of EIS \\
\hline Language & Difficult mutual understanding in knowledge transfer events and EIS descriptions \\
\hline Disciplinary background & $\begin{array}{l}\text { Difficult communication between transfer actors with social science and engineering } \\
\text { or design background }\end{array}$ \\
\hline Geography (of metabolic flows) & $\begin{array}{l}\text { The difference between geographical circumstances affects metabolic flows and } \\
\text { applicability of solutions }\end{array}$ \\
\hline Socio-cultural & $\begin{array}{l}\text { Differences in waste sensitivity, environmental culture, and other socio-cultural } \\
\text { specificities may make stakeholders non-receptive to some solutions }\end{array}$ \\
\hline Socio-economic differences & $\begin{array}{l}\text { A higher level of economic development tends to be related to more advanced } \\
\text { environmental culture; pragmatically, more wealthy regions are able to dedicate } \\
\text { more resources to innovation in circularity }\end{array}$ \\
\hline Other socio-political phenomena & \begin{tabular}{l} 
Public opposition to the transfer of foreign policies may block transfer \\
\hline Legal aspects
\end{tabular} \\
$\begin{array}{l}\text { A discrepancy in legislation between two of the two contexts may prevent } \\
\text { implementation of an imported solution }\end{array}$ \\
\hline Governance and decision-making & $\begin{array}{l}\text { Divergent governance arrangements may undermine the implementation of an } \\
\text { imported solution }\end{array}$ \\
\hline Technological aspects & $\begin{array}{l}\text { When the recipient region is at a lower stage of development of circular } \\
\text { technologies transfer is hindered }\end{array}$ \\
\hline
\end{tabular}

to maintain these areas (a socio-economic barrier) and the inherent regulations (a legal barrier). However, as stakeholders argued, using biologist expert(s) in the implementation of the solution would allow the overcoming of these barriers easily. Another legal barrier identified was the lack of clarity on the ownership of these areas, even if they are generally publicly owned.

The solution for the transformation of buffer zones for leisure activities faced more substantial legal barriers, mainly related to access and safety (e.g., safety of leisure activities next to highways). The original EIS aimed at activities such as cycling, however, the programme for the use of such buffer zones for leisure would need to be determined to conform with the legal requirements in the Naples region. In the Italian context, generally, access to such buffer zones is restricted for people on safety grounds. This barrier was deemed difficult to overcome. Moreover, a further barrier identified was socio-cultural: cycling as a leisure activity is much less popular in the Naples context than it is in Amsterdam.

\subsection{Transferability of Solutions}

\subsubsection{Naples to Amsterdam}

Concerning transferability of the RECALL solution, the Amsterdam stakeholders involved in the workshops generally saw it as highly transferable, since soil remediation is also needed for polluted land around Amsterdam, especially in the port area. In both regions, the traditions of manufacturing products from hemp fibres are also present. The barriers identified were deemed surmount- able. Practically, the entire solution was considered transferable, albeit with some extensions and adaptations to fit the local context and connect it to construction materials flow. Importantly, this connection to the C\&DW flow increased the potential of the solution to trigger innovation by linking wastescape regeneration to circular construction. Consequently, the EIS was added to the catalogue of solutions for the AMA.

Conversely, the REC.OVER solution was deemed hardly transferable due to the magnitude of the barriers identified. Since the original solution was largely context-specific, only some of the ideas behind this EIS were deemed transferable (e.g., providing support for handling C\&DW by individuals and support for informal waste collection from individuals engaged in small-scale construction work).

\subsubsection{Amsterdam to Naples}

The Neapolitan stakeholders agreed that both solutions for buffer zones from Amsterdam were generally transferable to the Neapolitan case in their entirety because neither of them relied on specific territorial features of the AMA. Furthermore, buffer zones around infrastructures can be found practically in every regional context. However, the solution aimed at leisure activities was deemed much less transferable due to the importance of the legal barriers described above. Moreover, it was hard to imagine the activities proposed in the original EIS in the Neapolitan case. In fact, the EIS was based on the Dutch socio-cultural context and the huge popularity of cycling and ubiquity of bicycle paths for leisure and com- 
muting. Conversely, cycling in the Neapolitan culture is not yet as deeply rooted as in the Netherlands.

\subsection{Adaptation of Solutions}

\subsubsection{Naples to Amsterdam}

Stakeholders identified a range of far-reaching adaptations transforming the RECALL solution to fit the AMA context, which departed substantially from the original solution. First, the metabolic focus of the solution was expanded to include manufacturing of hemp-based construction materials (e.g., hempcrete blocks combining chalk and hemp fibres), offering excellent isolation capacity and suitable for constructing and insulating warehouses or data centres (pollutants in fibres preclude use for housing). That reflected, on the one hand, the high importance of C\&DW flow in the Amsterdam region, and, on the other hand, the on-going spatial and industrial trends in the region, namely the growing demand for (circular) construction materials in the wake of the expected massive urban expansion (and the ambitions of the Municipality of Amsterdam to develop new urban areas following circularity principles) and the emergence of new clusters of economic activity (data centres). Interestingly, this expansion of the goals and scope of the solution was also later partly taken up by the Naples PULL to enhance the original EIS, connecting it to the C\&DW flow.

Second, stakeholders proposed to consider various approaches to remediation depending on the demand for land in a particular area. In a nutshell, in cases where there was high pressure on land needed for imminent development, a layer of soil could be stripped down and transported to a wastescape in a more remote location where development is likely to happen later, allowing for redevelopment of the wastescapes in the short term. There, remediation process with crops (adapted to pollution type) would take place, making those more remote wastescapes suitable for later development. Finally, to further broaden the potential support for the solution, proposals were made to combine hemp-based soil remediation with recreation activities or renewable energy production. This could be supplemented by a strategy entailing periodic rotation of hemp production on a given plot with solar energy harvesting, which could muster the support of renewable energy production cooperatives.

The stakeholders identified the Amsterdam port area as the most suitable space for deploying the solution. Also, while the traditional industry actors (hemp products) were critical for the original solution, in its Amsterdam-adapted version, producers of construction materials, builders and developers became important stakeholders, alongside grondbanken (soil banks), municipal institutions dealing with assessment and classification of batches of land based on environmental quality and with the logistics of soil flows to and from soil depots.
In the case of the REC.OVER solution, assuming that only some elements of this EIS could be implemented in the AMA context, it was proposed to consider a network of neighbourhood collection points and to use digital support tools to provide accurate and real-time information on the material available for reuse. Due to low transferability, however, the solution ended up not being included in the AMA catalogue of EIS.

\subsubsection{Amsterdam to Naples}

Adaptations deemed necessary to implement both solutions for buffer zones (e.g., in the industrial areas or in the motorway junctions) in Naples were not major as such, however, a process of translation also took place. First, adaptation was the combination of both solutions into one comprehensive solution for valorising buffer zones in a complementary and differentiated way, reflecting the spatial and legal restrictions. Since access to buffer zones located immediately next to transport infrastructure is not possible in the Italian legal context (for safety reasons), it was proposed to focus on creating spaces for biodiversity in the restricted access areas, while opting for leisure-oriented transformation of wastescapes close but not immediately adjacent to transport infrastructures where access restrictions did not apply.

Second, on the basis of spatial analysis of the potential areas for the transformation of buffer zones adjacent to infrastructure, the stakeholders stressed the necessity to create stronger connections among these fragmented buffer areas since they should ensure continuity for the passage of animals (e.g., connection to larger regional green networks). Stakeholders also agreed that with the involvement of biodiversity experts this should be easily manageable, as they would ensure the selection of suitable species compatible with the infrastructures.

Finally, it was proposed to integrate these solutions with the solutions proposed for the reuse of organic waste and C\&DW which foresees the reuse of compost and inert construction material for the creation of new soils for reshaping and regeneration of the landscape. The scope and goals of the original solutions from the Amsterdam PULL were thus also expanded. This expansion made the transferred solutions go beyond the original goal of wastescape regeneration, connecting to other waste flows in a systemic way. It was proposed, namely, to reuse a combination of C\&DW (as construction material) and organic waste (as compost) acquired through other EIS developed in the Naples PULL to develop new dynamic landscapes in the buffer zones, for instance creation of hills that would diversify the existing landscape, while providing space for biodiversity, recreation as well as a sound barrier for the transport infrastructure.

\section{Conclusions}

The article explored the process of knowledge transfer between Amsterdam and Naples, taking place within a 
network of living labs set up to develop experimental solutions and regional strategies for circular economy and better resource management. This unique setting offered an opportunity to: (1) explore the barriers encountered, (2) assess the degree of transferability of solutions, and (3) investigate how the solutions changed as they "travelled" through the relational space of the networked living labs.

Some of the solutions covered were highly transferable in their entirety and with only minor adaptations, while others were much less suitable for transfer due to significant contextual barriers. A typology of barriers for transfer of spatial solutions for a circular economy was elaborated and empirically tested, responding to the calls for a better understanding of the practicalities of knowledge transfer (e.g., Argote \& Fahrenkopf, 2016), especially in an emerging policy area like circular economy.

The typology of barriers was applied to the scrutiny of the process of transfer of a selection of ecoinnovative territorial solutions for circular economy between Amsterdam and Naples. The most prominent barriers, as observed in our cases, were geographic (e.g., scarcity of land), socio-economic (e.g., pressures on land development, availability of funding), socio-cultural (e.g., presence or absence of illegal dumping practices, cycling culture) and legal (e.g., lack of suitable regulations or presence of regulations preventing deployment of a solution). While the geographical and socio-economic barriers were surmountable-provided that the solutions were 'translated' to fit the local context better-the socio-cultural and legal barriers proved more difficult to overcome and limited the transferability of solutions. Naturally, the set of such barriers will vary from case to case, but the typology proposed can be applied in other cases as a first step towards assessing the transferability of solutions across places and the consideration of adaptations needed for a solution to work in the recipient context.

Applied to the Amsterdam-Naples knowledge transfer, the barriers identified pointed to the need for more or less wide-ranging adaptations of the solutions, from cases where transfer was deemed impossible due to the magnitude of the socio-cultural barriers, as in the case of the Naples solution for tackling illegal dumping of construction waste; to cases where a process of far-reaching adaptation took place, largely transforming the original goals and modalities of the solution, as for instance with the transfer of the Neapolitan solution for soil remediation with hemp to Amsterdam region or that of solutions for buffer zones transferred from Amsterdam to Naples. The adaptations proposed to make imported solutions work in the recipient context were co-developed by the stakeholders from the recipient region, with participation and feedback from stakeholders from the sender region, to: (1) ensure contextual appropriateness, (2) broaden the impacts, and (3) the potential support for the solution among wider stakeholder groups. Thus, the article provided an empirical illustration of the process of policy translation, as advocated by
Stone (2012), in which solutions are not mechanistically grafted, but rather redesigned in this process.

One of the key observations made is that transferability is high if a solution does not rely on place-specific characteristics of the sender region, but rather builds on resources, practices and territorial features that are present in the recipient region, too. That said, substantial differences between the sender and recipient context do not preclude transfer per se, but rather point to the need for using the original solution as a basis or inspiration to develop an almost entirely new solution, building on the original idea but substantially departing from it, by rethinking and/or expanding its goals and focus. In such cases, knowledge transfer is less about transferring a solution 'from place $A$ to place $B$ ' and more about using a solution from 'place $A$ ' (and in our case, also the feedback from the stakeholders from 'place $A$ ') as an inspiration for learning and co-design of an innovative solution for 'place B'.

Finally, the article sheds light on the process of adaptation of the solutions transferred and the role of the networked living labs as socio-spatial nodes for knowledge transfer. The inter-connected living labs, set up to co-design circular economy solutions with regional stakeholders in Amsterdam and Naples, anchored the knowledge transfer process in a parallel process of policy innovation in both regions, addressing similar challenges and using similar methodology. The labs provided a relational and physical space for interactions between stakeholders from the two regions. This allowed for a relatively deep understanding of both contexts and the solutions emerging from them, facilitated by the stakeholders from the sender regions. It also facilitated the building of shared understanding among the stakeholders from both regions. This made the transfer process not only more strategic but also more creative, learningoriented, prompting outside-the-box thinking and being more likely to lead to the successful implementation of the solutions based on the knowledge co-created through interaction between stakeholders from different contexts. Thus, the networked living labs as a knowledge transfer method allowed for reflexivity, as opposed to one-way learning channels or transfer process with limited feedback opportunities. This allows for jointly finding ways to overcome transfer barriers and avoiding the pitfalls of ill-informed copy-pasting of 'best practices' from abroad (see Stead, 2012).

A caveat is that the solutions studied were preselected from a larger catalogue elaborated in each region in order to minimise the potential barriers. Thanks to this pre-selection, and the repeated interactions between the stakeholders, the transfer process was fruitful, despite the initial scepticism of the stakeholders involved about the purpose of transferring solutions between such vastly different regions. Another caveat is that the transfer took place in a 'controlled environment' whereby the transfer activities were institutionalised in a network of living lab experiments as part of a large inter- 
national research project. This created scope for applying a pre-determined methodology for the transfer events and nudging the participants to ponder specific questions about barriers, transferability and adaptation of solutions. However, the process relied heavily on the substantial financial and organisational resources deployed as part of the project, which may not be available in other situations. This experiment, however, allowed for organising a detailed participant observation of this process, collecting unique insights on the above questions from the interactions with and between real-world regional stakeholders from two European regions. This, in turn, allowed for experimentation and drawing a number of lessons for theory and practice, as described above. Moreover, the study provides a template for the process of knowledge transfer between territories which could be deployed in the context of various events and networks oriented towards knowledge exchange between urban and regional practitioners (e.g., international city networks, study visits, territorial cooperation and/or city twinning activities).

Future research could apply this method to facilitate the transfer of knowledge between other regions and cities, possibly also covering on other aspects of sustainable urban and regional development and, ideally, examining how the solutions transferred were ultimately implemented on the ground. Such research would validate the potential of networks of living labs as a knowledge transfer device shown in this study.

\section{Acknowledgments}

This research was conducted as part of the REPAiR (REsource Management in Peri-urban AReas: Going Beyond Urban Metabolism) project funded by European Union's Horizon 2020 Research and Innovation Programme, under grant agreement no. 688920. The authors would like to thank the participants of the PeriUrban Living Labs in Naples and Amsterdam who took part in the knowledge transfer activities as well as the members of the REPAiR project's TU Delft and UNINA teams for their cooperation and support. Viktor Varjú would like to thank his Bolyai János Research Scholarship, which he received during the research.

\section{Conflict of Interests}

The authors declare no conflict of interests.

\section{References}

Amenta, L., \& Van Timmeren, A. (2018). Beyond wastescapes: Towards circular landscapes. Addressing the spatial dimension of circularity through the regeneration of wastescapes. Sustainability, 10(12), 4740. https://doi.org/10.3390/su10124740

Argote, L., \& Fahrenkopf, E. (2016). Organizational behavior and human decision processes knowledge trans- fer in organizations: The roles of members, tasks, tools, and networks. Organizational Behavior and $\mathrm{Hu}$ man Decision Processes, 136, 146-159.

Argote, L., \& Ingram, P. (2000). Knowledge transfer: A basis for competitive advantage in firms. Organizational Behavior and Human Decision Processes, 82(1), 150-169.

Bellini, A., Aarseth, W., \& Hosseini, A. (2016). Effective knowledge transfer in successful partnering projects. Energy Procedia, 96(1876), 218-228.

Dolowitz, D. P., \& Marsh, D. (2000). Learning from abroad: The role of policy transfer in contemporary policy-making. Governance, 13(1), 5-23.

Dolowitz, D. P., \& Marsh, D. (2012). The future of policy transfer research. Political Studies Review, 10(3), 339-345.

EC. (2011). Innovation for a sustainable future: The eco-innovation action plan (Eco-AP). Brussels: European Commission. Retrieved from https://eur-lex. europa.eu/legal-content/EN/TXT/PDF/?uri=CELEX: 52011DC0899\&from $=\mathrm{EN}$

EC. (2012). Eco-innovation the key to Europe's future competitiveness. Brussels: European Commission, Environment, Publications Office.

EEA European Environment Agency. (2017). Increasing fragmentation of landscape threatens European wildlife. Copenhagen: EEA.

ENoLL. (2019). The European network of living labs: The first step towards a new innovation system! European Network of Living Labs. Retrieved from https:// enoll.org

Eriksson, M., Niitamo, V., Kulkki, S., \& Hribernik, K. A. (2006). Living labs as a multi-contextual RandD methodology. Milan: IEEE International Technology Management Conference. http://dx.doi.org/10. 1109/ICE.2006.7477082

Evans, M. (2009). Policy transfer in critical perspective. Policy Studies, 30(3), 243-268.

Geissdoerfer, M., Savaget, P., Bocken, N. M., \& Hultink, E. J. (2017). The circular economy: A new sustainability paradigm? Journal of Cleaner Production, 143, 757-768.

Healey, P., \& Upton, R. (2010). Crossing borders: International exchange and planning practices. London: Routledge.

Heinelt, H., Held, G., Kopp-Malke, T., Matthiesen, U., Reisinger, E., \& Zimmermann, K. (2006). Governance for sustainability. Conceptual frame. Paper presented in consortium meeting at the G-FORS Project FP6, September 2006, Darmstadt and Erkner.

Howlett, M., \& Rayner, J. (2008). Third generation policy diffusion studies and the analysis of policy mixes: Two steps forward and one step back? Journal of Comparative Policy Analysis: Research and Practice, 10(4), 385-402.

Inkpen, A. C., \& Tsang, E. W. K. (2005). Social capital, networks, and knowledge transfer. Academy of Management Review, 30(1), 146-165. 
Kumar, R. (2014). Research methodology: A step-by-step guide for beginners (4th ed.). London: Sage.

Lepik, K.-L., Krigul, M., \& Terk, E. (2010). Introducing living lab's method as knowledge transfer from one socio-institutional context to another: Evidence from Helsinki-Tallinn cross-border region. Journal of Universal Computer Science, 16(8), 1089-1101.

Marino, M., Parotta, P., \& Pozzoli, D. (2016). Educational diversity and knowledge transfers via interfirm labor mobility. Journal of Economic Behaviour and Organization, 123, 168-183.

McCann, E. (2011). Urban policy mobilities and global circuits of knowledge: Toward a research agenda. Annals of the Association of American Geographers, 101(1), 107-130.

McCann, E., \& Ward, K. (2012). Assembling urbanism: Following policies and 'studying through' the sites and situations of policy making. Environment and Planning $A, 44(1), 42-51$.

Peck, J. (2011). Geographies of policy: From transferdiffusion to mobility-mutation. Progress in Human Geography, 35(6), 773-797.

REPAiR. (2017). REsource management in peri-urban $A R$ eas: Going beyond urban metabolism. D 5.1 PULLS handbook. Naples: UNINA.

REPAiR. (2018a). REsource management in peri-urban AReas: Going beyond urban metabolism. D5.3 Ecoinnovative solutions Naples. Naples: UNINA.

REPAiR. (2018b). REsource management in peri-urban AReas: Going beyond urban metabolism. D5.2 Eco-innovative solutions Amsterdam. Delft: TU Delft. Retrieved from http://h2020repair.eu/wp-content/ uploads/2019/03/Deliverable-5.2-Catalogue-of-
solutions-and-strategies-for-Amsterdam.pdf REPAiR. (2018c). REsource management in peri-urban AReas: Going beyond urban metabolism methodology. D7.1 Theoretical model of knowledge transfer. Delft: TU Delft. Retrieved from http://h2020repair. eu/wp-content/uploads/2019/03/Deliverable-7.1Theoretical-model-of-knowledge-transfer.pdf

Russel, B. H. (2006). Research methods in anthropology. Qualitative and quantitative approaches (4th ed.). New York, NY: Altamira Press.

Schumacher, I. (2015). The endogenous formation of an environmental culture. European Economic Review, 76, 200-221.

Stead, D. (2012). Best practices and policy transfer in spatial planning. Planning Practice and Research, 27(1), 103-116.

Steen, K., \& van Bueren, E. (2017). Urban living labs: $A$ living lab way of working. Amsterdam: Amsterdam Institute for Metropolitan Solutions. Retrieved from https://www.ams-amsterdam.com/wordpress/wpcontent/uploads/AMS-Living-Lab-Way-of-Workprint.pdf

Stone, D. (2012). Transfer and translation of policy. Policy Studies, 33(6), 483-499.

Temenos, C., \& McCann, E. (2013). Geographies of policy mobilities. Geography Compass, 7(5), 344-357.

van Geenhuizen, M. (2018). A framework for the evaluation of living labs as boundary spanners in innovation. Environment and Planning C: Politics and Space, 36(7), 1280-1298

Yakhlef, A. (2007). Knowledge transfer as the transformation of context. Journal of High Technology Management Research, 18, 43-57.

\section{About the Authors}
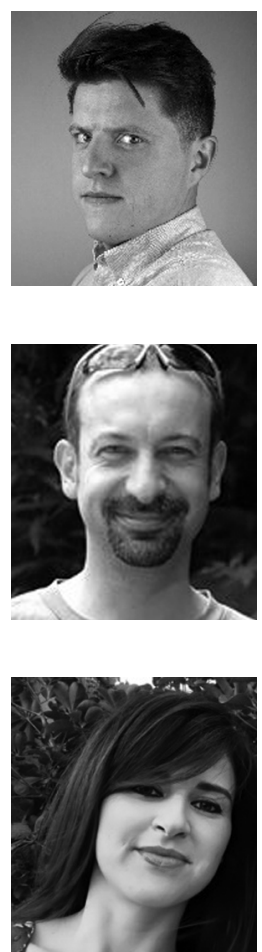

Marcin Dąbrowski (Dr.) is an Assistant Professor at the Chair of Spatial Planning and Strategy in the Department of Urbanism, Faculty of Architecture and the Built Environment, TU Delft, where he conducts research and teaches in the fields of spatial planning and territorial governance. He has a background in political science and regional studies, however, his research interest spans across many topics related to the governance of territory, from regional strategies to circular economy, or energy transition, to regional development policies, governance of urban climate change adaptation and the evolution of spatial planning systems in Europe.

Viktor Varjú (PhD), is a Senior Research Fellow at the Institute for Regional Studies (MTA KRTK). He holds a PhD in Earth Sciences and master's degrees in geography and sociology. His main research areas are social aspects of regional development, renewable energy, circular economy and other environmental-related topics. He has published on environmental sociology and environmental policy integration in regional and spatial development.

Libera Amenta (Dr.) is a Post-Doc Researcher in the Department of Architecture at the University of Naples Federico II, in Italy. She has been, until recently, also a Post-Doc Researcher in the Department of Urbanism, at TU Delft in the Netherlands. Since 2016, she has been carrying out research on topics regarding the circular regeneration of wastescapes as a member of the EU-funded Horizon 2020 REPAiR project. 